Revista de la red interuniversitaria de estudios sobre las

literaturas rioplatenses contemporáneas en Francia

$12 \mid 2015$

Prodigios borgeanos: ficciones, historias, teologías

\title{
Contra el propio canon : Borges en el Laboratorio de Traducción
}

\author{
Delfina Muschietti
}

\section{OpenEdition}

\section{Journals}

Edición electrónica

URL: http://journals.openedition.org/lirico/1889

DOI: $10.4000 /$ lirico.1889

ISSN: 2262-8339

Editor

Réseau interuniversitaire d'étude des littératures contemporaines du Río de la Plata

\section{Referencia electrónica}

Delfina Muschietti, «Contra el propio canon : Borges en el Laboratorio de Traducción », Cuadernos LIRICO [En línea], 12 | 2015, Puesto en línea el 23 enero 2015, consultado el 30 abril 2019. URL : http:// journals.openedition.org/lirico/1889; DOI : 10.4000/lirico.1889

Este documento fue generado automáticamente el 30 abril 2019.

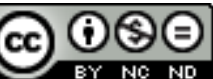

Cuadernos LIRICO está distribuido bajo una Licencia Creative Commons Atribución-NoComercialSinDerivar 4.0 Internacional. 


\title{
Contra el propio canon : Borges en el Laboratorio de Traducción
}

\author{
Delfina Muschietti
}

Este trabajo se inscribe en la propuesta de una nueva Escuela de Traducción Poética. Las premisas teóricas de Walter Benjamín (1923) y Giorgio Agamben (1978) enmarcan nuestra tarea como una Nueva Filología. Será fundamental en ella el estudio interdisciplinario en el que confluyen filosofía, historia, psicoanálisis, estética y teoría literaria. Una filología absorta en la facticidad y la devoción mágica por los particulares, por el detalle, que Agamben destaca como fundamentales en Benjamin. El poema es una caja de resonancia y desde ella el sentido estalla, viaja, difiere. El poema parte las palabras, se parte, arma y desarma melodías, tonalidades, e insiste en la repetición como técnica clave del ritmo, que desde Tinianov (1923) será principio compositivo dominante en el poema. Para traducir un poema hay que estar atentos a esas intensidades que llegan de esa forma singular que se juega en la repetición sonora o de sentido, y desmontarla, hacerla hablar 1

- Traducir el poema será hallar una nueva forma que, como afirma Benjamin, debe capturar el modo-de-decir del original,fórmula que he ampliado enel modo de repetir del original

. El lector-receptor debe aguzar la capacidad para leer dicha singularidad, esas intensidades de la repetición, formas del fantasma que van y vienen entre posiciones móviles (la del poeta, la del crítico-traductor-escritor) que se intersectan y ponen en contacto diferentes horizontes culturales y diferentes tendencias frente a la lengua. Para ello es necesario adoptar una posición de escucha flotante

(término que tomo de Freud), libre de prejuicios culturales y de lectura, para captar la extrañeza y el mapa rítmicoque diseña el original (Muschiettiet al

. 2013). En el acto de traducir poesía se cruzarían las siguientes posiciones y momentos, siempre móviles, nunca fijos : 
I. Ocupamos el lugar de lectores-críticos. Nos enfrentamos a una forma, que remite a un estado de la lengua original, la del poema. Estado de la lengua, estado de la norma literaria y poética, relaciones contiguas con contextos sociales y culturales que involucran cuerpos, géneros, subjetividad, memoria individual y colectiva. Sólo la lengua del poema nos provee de modos de acercamiento a eso previo al poema

. Del texto y sus intensidades localizadas en la repetición de la palabra, parten envíos que nos llevan a esa trama previa a la que nunca llegaremos ni conoceremos; las intenciones o propósitos previos al poema tampoco tienen importancia porque el poema-efecto es un

objeto desconocido para el mismo poeta. La trama abstracta de la que surge el mapa rítmico del poema es lo que he llamado partitura flotante, y es la huella del contacto del artista con esa dimensión desconocida unknown

- de la que hablan Emerson en 1844, Cage en 1955, Deleuze en el texto de 1993 y luego en el de 1995 : campo trascendental en el plano de inmanencia. He llamado a ese plano disparador plataforma flotante ${ }^{3}$

. El lector sólo tiene la huella de ese contacto en la forma ya dada, el poema dictado : de allí salen envíos disparados en la repetición y ese esqueleto fantasmático compone la partitura flotante, a la vez pura potencia que se eleva de la forma y se dice en una respiración. El traductor tiene que detenerse allí para dejarse tomar por esa voz, por ese respirar ligado a ciertos estados de la lengua, a ciertos contextos que llegan aletargados en los envíos de la arquitectura rítmica del poema. Primero, entonces, habría que detenerse a escuchar, a leer, a componer el fantasma de la repetición, la partitura del mapa rítmico, antes de partir de la lengua de partida. Y por sobre todo, escuchar la extrañeza que se pega y se desprende de cada momento de la repetición. Foucault ya nos enseñaba en

\section{Arqueología del saber}

(1969) la importancia de leer lo que está allí de hecho en un discurso y preguntarse por qué esa palabra, esa lengua allí y no otra entre las muchas posibles. Preguntar al dato inmanente de la forma para construir un sentido, una lectura, y de allí los desvíos que llevan al contexto. El debate no es, entonces, acerca de si ser o no literales, sino más bien de discutir qué se entiende por literalidad. Se trata, en última instancia, de ser fieles a una literalidad productiva. extrañeza que deriva de la repetición, y que he dado en llamar

II. Nos movemos de lectores-críticos a escritores dadores de forma. De la potente materialidad del poema, sólo nos queda en el oído el fantasma de su repetición, ésa que anuda sonido, sentido y grafema. Habrá que darle nueva forma en la lengua de llegada. 
. Sólo que se trata, como bien dice Benjamin una vez más, de una forma derivada o segunda ; lo cual para nada indica una sacralización del original en desmedro de la traducción, como algunas equívocas lecturas de Benjamin insisten en señalar. Porque la maestría del traductor reside en un trabajo sutil : recomponer el fantasma de la repetición, el mapa rítmico del poema, y en la tarea del traslado tornarse invisible mientras su lengua se transforma. Dejarse tomar por la forma primera y su lengua, ahuecar la propia, alojando ese fantasma desprendido de la repetición primera. Componer una misma forma pero otra, en la economía de la repetición, como quería Deleuze (1969) : economía del robo y la diferencia, por oposición a la economía de la equivalencia o del intercambio. Si no hay equivalencias entre las lenguas -como el mismo Borges reconoce-,

hay cercanías oblicuas, choques, expansión de connotaciones que se irradian casi sin querer por fuera del radio del original, y que el traductor debe controlar. Es allí donde el traductor se vuelve equilibrista, minucioso técnico de la repetición.

Es allí cuando gana y cuando pierde, cuando aparece la resta y el exceso (Caresani en Muschietti et al.

2013). Un luminoso fracaso, sabido de antemano y que igual no obstaculiza el afán de traducir. Y en tanto el traductor mantenga la decisión de no neutralizar el texto de partida, respetar ambigüedades e impactos, llegará al objetivo deseado : mantener abierta la más abierta de las formas que es la poesía. Borges la llama « enigma

». Igualmente, toda traducción es una lectura del original, es parte de su crítica y, como tal, una expansión de la obra (Benjamin, otra vez), y en algún punto significa un cierre. El desafío del traductor es que ese cierre sea apenas como un temblor : una levedad sustentada, sin embargo, por intensas investigaciones sobre los modos de la lengua, trabajo con diccionarios múltiples, despliegue de posibilidades. Por allí se cuela también

aquella renuncia

que está en el título del original alemán del texto de Benjamin « La tarea del traductor ».

Es lo que nos advierte Paul de Man (1990) en su artículo. O sea que al traducir « tarea » perdemos la línea que en alemán se tiende hacia el campo semántico de la renuncia, del rendirse. ¿Ante qué ? Ante la imposibilidad de la equivalencia para el hecho de traducir poesía : sólo vale trasladar el fantasma de la repetición desde la lengua-forma de partida a la lengua-forma de llegada.

Duelo

lo llamará Ricoeur (2005), con otro término freudiano. Habrá que rendirse también ante el

fin del

traductor-narcisista

que hace escuchar su voz en lugar de la respiración del original. Por el contrario, el traductor-invisible

trabaja minuciosamente y con pasión (sin pasión por el original no hay traducción feliz) para ser fiel a una respiración fantasma. A partir de allí la tarea-traslado implica opciones, elecciones en el elenco de palabras y giros sintácticos que la lengua de llegada le ofrece para el traslado del mapa rítmico

.Walter Romero nos dirá que « el traductor se hace cargo de misteriosas aliteraciones »

(Romero en Muschietti 
et al.

2014). Así como, según Mallarmé y Valéry, el poema-efecto es un misterio para el mismo poeta escritor (Percia en Muschietti et al

. 2014), lo será también para el lector-traductor, que debe hacerse cargo de ese misterio en el ritmo. Es así como el traductor se vuelve investigador de su propia lengua. Traducir poesía nos obliga a alejarnos de nuestra lengua, para mirarla, escucharla desde fuera, como extraños a ella ; y poder así calibrar, medir, escuchar las diferentes opciones a la hora de traducir

. Un momento más en el que el traductor se toca con el creador : volverse extraños en la propia lengua, como quería Rilke, para luego empezar a escribir, para luego hallar una lengua

(Rimbaud), esta vez lo más adherida posible a la lengua hallada por el original, se trata de repetir ese hallazgo en otra lengua. $Y$ en un momento propio e inherente a la tarea de traducir, alojar la lengua del original y dejar que ésta violente la lengua propia. Los defensores de la traducción-narcisista preferirán que el traductor invente sobre las dificultades del original, en lugar de aceptar el desafío que la forma de éste le ofrece a la investigación y el detalle de las lenguas. Paradójicamente, la renuncia del traductor de poesía implica no renunciar nunca ante el desafío de la dificultad. Los defensores del traductor-explicador

preferirán antes que la extrañeza ambigua que el original propone, una forma neutralizada y « comprensible ». Si un sentido nunca es trasladable, como nos enseña Derrida (1971), menos aún en la poesía, cuya singularidad implica atar sonido a sentido y a grafema, y volver el sentido indecidible : en constante fuga, misterio que llega desde la plataforma inmanente y flotante que invierte la noción de sentido común en caos, y el estar tendido en el plano del sueño, en libertad de creación. Mantener el dictado de esa indecibilidad es el desafío del traductor. Y no escribir en « buen español » porque el poema que traduce no fue escrito en español, ni responde al estado de la lengua del traductor. Hay intercambio y violencia mutua entre los estados de las lenguas, alojos y desalojos. Por eso el español del traductor debe ser el más universal y abstracto

posible- como el mismo Borges lo admitía al final de su carrera, luego de tantas idas y vueltas al respecto y poniendo fin así a una de sus contradicciones

- para que en él pueda inscribirse como en juego de veladuras y transparencias, el eco del original. Es el español el que aloja la lengua del original y allí se transforma.

III.

Cuando comparamos traducciones, pasamos a una posición tercera, otra vez en el lugar de lectores-críticos. Si la tarea del traductor responde a determinadas elecciones, en esta posición tercera podremos apreciar los modos en que el horizonte cultural y retórico de cada escritor-traductor 
(esto es, su forma de leer, su orientación en el campo estético e intelectual al que pertenece) ha velado o no ciertas intensidades del original y la captura de su su mapa rítmico, y en el caso de que haya velamientos, observar en qué dirección apuntan sus elecciones en el momento de traducir. Se configura así otro fantasma, el de las elecciones del traductor y se trata aquí, otra vez, de hacer hablara esa nueva repetición hallada en cada traducción.

Paul Ricoeur ha dicho enSobre la traducción

(2005) que no se puede establecer criterios para traducir, y que por ende sólo se puede decir que una traducción es buena o mala ; o una es mejor que otra, e incluso tratar de mejorar a la más pobre. Pero, ¿sobre qué bases juzgar buena o mala una traducción, sobre qué bases actuar para mejorar la mejorable ? Es obvio que este juicio se levanta sobre una serie de criterios subyacentes en cada traductor a la hora de ponerse a traducir, o de criticar las traducciones de otros; en ese sentido, resulta interesante leer los diferentes textos escritos por Borges en diferentes momentos de su obra acerca de la traducción : encontramos allí un juego de contradicciones reveladoras. Para seguir este verdadero laberinto, ponemos el acento - otra vez tal como nos enseñaba Foucault- en los textos marginales, laterales, de su producción : breves reseñas y colaboraciones en la revista El Hogarentre 1936 y 1940 (los bien llamadosTextos cautivos ), sus prólogos, conferencias, y las colaboraciones en la revistasur

(1931-1980), que incluyen también algunas traducciones de poesía, que van de 1931 a 1947. Es notable el caso del breve prólogo que escribiera para la primera edición de las traducciones de Emily Dickinson publicadas por Silvina Ocampo en 1985. En un trabajo anterior habíamos analizado comparativamente las traducciones casi simultáneas realizadas por Amelia Rosselli y Silvina Ocampo de la poesía de Emily Dickinson

(Muschietti 2006 ; Muschietti

et al.

2013). Observábamos que, mientras Rosselli respeta la extrañeza del texto de Dickinson, aún hoy hermética para los hablantes nativos de inglés norteamericano

, su dicción cortante y su tono agudo e irónico, encontramos en la traducción de Silvina Ocampo las tendencias del poeta explicador o neutralizador, notable en la eliminación de las mayúsculas dickinsonianas. Estas, junto a los guiones, aparentemente arbitrarios, que cortan la sintaxis, constituyen rasgos de estilo relevantes en Dickinson, e implican un quantum formal 
de ruptura muy llamativo. Es éste un rasgo especial, si notamos que Dickinson pone mayúsculas a palabras que designan objetos comunes y animales, y en especial partes del cuerpo o prendas del vestido femenino, palabras de uso muy cotidiano (Shoes, Dog, Heel, Ankle, Boddice, Belt, Hat, Gown), y las mezcla con otras de registro muy diferente (God, Science, Surgery, Senses, Soul, Cathedral), de una manera muy poco convencional para una mujer escritora de fines de 1800 en Estados Unidos. En segundo lugar, el otro rasgo

fundamental son los guiones que cortan, también con similar apariencia de

arbitrariariedad, la sintaxis del verso ; y así la suspenden y ambiguan, muy en clave mallarmeana. Ambos rasgos irán a la escritura también de ruptura de Sylvia Plath (otra poeta traducida por Rosselli). Mientras Ocampo sólo respeta el rasgo-guión, Rosselli lo

hace tanto con los guiones como con las mayúsculas. Con lo cual, podríamos decir,

Ocampo se queda a medio camino en el seguimiento de la ruptura experimental propuesta por Dickinson. Las mayúsculas y los guiones repiten e insisten en el corte de la respiración del flujo gráfico y sonoro, un corte que implica ruptura con el sentido común que asfixia. Son formas de indicar voces en alto, silencios y nuevas melodías, como las que

la misma Dickinson ensayara en su piano

. Las mayúsculas también dibujan con su repetición de letras, insisten en la materialidad de la palabra, sonido o grafema. Del mismo modo, los versos de Dickinson insisten en un ritmo corto (seis o siete sílabas son sus preferidos), a veces combinados con otros muy

largos cortados por los guiones. Ocampo no respeta esa dicción, Rosselli tiene más cuidado. Ocampo se deja llevar sin más por las dimensiones de las palabras y la sintaxis en español ; así como muchas veces se decide por ciertas salidas de invención que normalizan la dificultad de Dickinson

10

. Por eso llama la atención la acusación elogiosa de « literalidad » que hace Borges en el Prólogo a estas traducciones. Sobre ello volveremos más adelante.

Desde aquí partimos, entonces, para considerar las posiciones contradictorias que Borges ha planteado en relación con la traducción. Una contradicción que opera en la distancia entre sus afirmaciones programáticas y archifamosas en donde insiste en que no puede haber una teoría de la traducción (tal como dice Ricoeur) y el planteo de que la traducción vale tanto como el original $; y$, por otro lado, su trabajo en el propio Laboratorio de Traducción, analizando traducciones realizadas por otros, en donde exhibe fuertes juicios de valor, sustentados evidentemente sobre criterios de cómo se debe traducir que constituyen así una proto-teoría. En algunos casos, cuando critica las

malastraducciones y sus abusos, se puede observar

que las correcciones son casi puramente formales, muy en el estilo de la teoría de Tinianov, o Benjamin. Se trata de apuntes que hacen a la necesidad de atenerse a la forma de decir del original

. Como dice bien Sergio Pastormerlo (2001), Borges sólo puede dejar de considerar original y nombre de autor cuando se trata de autores poco importantes. En cambio, corroboro, cuando se trata de San Juan de la Cruz, Baudelaire, Whitman o Shakespeare, autores faros de su Biblioteca, allí la noción de autor y original se erige con gran importancia. Así comenta en 1968 en el Prólogo a la edición de

Hojas de hierba

de Whitman con su traducción, que, luego de asistir a una representación deMacbeth 
, y a pesar de que la « traducción era no menos deleznable que sus actores y que el pintarrajeado escenario [...] salí a la calle deshecho de pasión trágica. Shakespeare se había hecho camino ». Para terminar diciendo que a través de su propia pobre traducción

«Whitman también lo hará" (Borges 1996 : 160). Esta importancia del original desdice puntualmente lo proclamado en el Prólogo a

\section{El cementerio marino}

de Valéry, esta vez en 1932 (1996 : 151-154), en el que se juega con la idea de que la traducción puede ser mejor que el original y que éste no tiene ninguna primacía. Otros casos muy notables que contradicen esta afirmación aparecen en muchos comentarios específicos sobre otras traducciones. Por ejemplo, los que hace en

Suren 1942 a la traducción deCanto a mí mismo

de Walt Whitman, realizada por León Felipe y publicada en Losada en 1941 (Borges 1999 : 245-247). Allí Borges adopta la posición de traductor-invisible- la que hemos elegido con Benjamin para nuestra propuesta- ${ }^{11}$ , cuando identifica su traducción con el original : «Whitman escribe » (245) es la frase que antecede a las citas de su propia traducción para contrastarla con la de León Felipe. Borges-Whitman denuncia una serie de problemas, que diseñan claros criterios básicos que deben regir la traducción de poesía :

1) Critica la aparición en Felipe de un « aire Núñez de Arce », completamente ajeno al verso de Whitman (246).

2) Insiste en que se debe respetar la extrañeza del original, sin cambiar su tono o agregar elementos, como hace Felipe -dice burlón- quien "le regala onomatopeyas » a Whitman

3) Señala la importancia de respetar la brevedad de la sintaxis y de la estrofa de Whitman, que « Felipe corrige » (246), cuando convierte en cinco versos lo que en el texto de partida son dos versos : « La transformación es notoria ; de la larga voz sálmica hemos pasado a los engreídos grititos del cante jondo » (247). Es obvia aquí la atención que Borges pone en la respiración y el ritmo del original, también evidente en la serie de traducciones publicadas en 1931 con su firma en

Sur

: allí, con las traducciones enfrentadas a su original, se puede ver cómo Borges respeta el dibujo del poema y su respiración, con la alternancia de versos breves y largos. En la cita sobre el tono del cante jondo, confirmamos también que ya en la década del cuarenta, aún a pesar de sus proclamas, Borges piensa desde su Laboratorio de Traductor que la lengua del traductor no debe invadir con tono vernáculo (en este caso el del español de España) el otro tono del original (el del inglés norteamericano de Whitman), aseveración que hará con todas las letras en sus últimos ensayos, mientras reconoce el error de sus pasadas proclamas provocativas. Por el otro lado, y de acuerdo con la premisa benjaminiana, Borges observa que el lenguaje del traductor sí debe dejarse invadir por el del original. Es el caso de la lectura de la traducción de su obra al alemán. En 1976, en « El oficio de traducir » (1999 : 321-325) consigna, con una especie de tierna ironía, que un traductor ha elegido escribir en alemán « llegaba el crepúsculo » en uno de sus cuentos, cuando el original decía « llegaba un oscuro » (325), refiriéndose a un tipo de pelaje del caballo criollo y luego concluye : 
Claro, traducía por el diccionario. Pero es el diccionario mismo el que induce a error. De acuerdo a diccionarios los idiomas son repertorios de sinónimos, pero no lo son. Los diccionarios bilingües, por otra parte, hacen creer que cada palabra de un idioma puede ser reemplazada por otra de otro idioma

. El error consiste en que no se tiene en cuenta que cada idioma es un modo de sentir el universo o de percibir el universo. (325)

Es decir, estamos con Deleuze (no a la economía del intercambio) y con Benjamin (se trata

modo de decir

), y más aún cuando se trata de poemas, en los cuales Borges afirma que aislar un verso de

su contexto es « cosa inadmisible ». Porque además -como ya dijimos con Rimbaud- un poema es una lengua hallada en el marco de una lengua mayor, por lo tanto se trata de un modo de decir aún más singular.

4) En la lectura de otras traducciones Borges vuelve a insistir en la importancia fundamental del ritmo y del sonido en el poema. Tomamos aquí los ejemplos de dos traducciones al inglés del poema « Noche oscura del alma » de San Juan de la Cruz, que él considera uno de los poetas más grandes en lengua castellana. En la significativa conferencia « La música de las palabras y la traducción » (Borges 2001 [1968] : 75-95), cita una estrofa del poema admirado y luego comenta la traducción al inglés del último verso " estando ya mi casa sosegada », que aunque suene casi mediocre así aislado - dice-, tenemos « el sonido siseante de las tres eses de "casa sosegada" » (78). Resalta así Borges el sonido, « el ritmo creado por la repetición » (aunque se olvida de la primera sde « estando », son cuatro y no sólo tres lassdel verso). Luego afirma :

Este poema fue traducido al inglés por Arthur Symons a finales del siglo XIX. La traducción

no es buena, pero si quieren examinarla, pueden encontrarla en el

Oxford Book of Modern Verse

de Yeats. Hace algunos años, un gran poeta escocés y también sudafricano, Roy Campbell, emprendió una traducción de la

Noche oscura del alma.

Me gustaría tener el libro aquí, pero nos limitaremos al verso que acabo de citar, " estando ya mi casa sosegada », y veremos qué hizo con él Roy Campbell. Lo tradujo así : « When all the house was hushed » (« cuando toda la casa estaba

callada »). Encontramos la palabra « all », que da sensación de espacio, sensación de inmensidad, al verso, y enseguida la hermosa, la preciosa palabra inglesa

« hushed ». « Hushed » parece ofrecernos la verdadera música del silencio (79) 13 .

Entonces, lo que Borges destaca en la traducción de Campbell es el modo en el que su elección traslada la respiración rítmica del original, dada en el inglés por las repeticiones

house-hushed/ house-was

. Y si « hushed» (callada o en silencio) es un poco menos que « sosegada » (que implica tranquilidad y silencio), la palabra

all

completa esa falta. Pero, curiosamente, la aludida traducción de Symons, aquí calificada como "no buena", aparece en la reseña de mayo de 1937 del mismo libro que cita despuésThe Oxford Book of Modern Verse 
by W.B. Yeats- (1996 : 291-292), cuando le dice al lector que elija cada uno los poemas preferidos entre los 400 que enlista la antología, y los 100 poetas autores. El hace su propia lista con la frase : « En cuanto a mí, he sentido

físicamente

la poesía - y realmente no hay otro canon- en » y enumera poemas de Francis Thompson, Dawson, Chesterton, Pound, Eliot, Turner, Joyce, Roy Campbell, « discípulo de Rimbaud », Dorothy Wellesley, y termina la lista con una traducción :

También, siquiera de reflejo, en una traducciónno infiel de 'La noche oscura del alma'. Básteme repetir la última estrofa. Escribió San Juan de la Cruz:

Quedéme y olvidéme,

rostro recliné sobre el Amado :

Cesó todo y dejéme,

Dejando mi cuidado

Entre las azucenas olvidado

All things I then forgot,

My cheek on him who for my coming came;

All ceased and I was not,

Arthur Leaving my cares and shame

Symons traduce: Among the lilies, and forgetting them.

Parece interesante que el elogio con el que Borges califica esta traducción (que luego será

« no buena », quizás por la comparación con la posterior de Campbell) sea la paradójica

no infiel.Por un lado, aquí aparece el parfidelidad-infidelidad

afirmación

que Borges usa a menudo, refiriéndose a traducciones. En este caso hay una doble negación barroca en la afirmación :

no in-fiel, e implica una resta suavizada de la falta defidelidad

de Symons para con el original, que Borges vio muy bien, y que luego declararía sin ambages (

no buena

). Por otro lado, resulta un elogio de la fidelidad en la traducción. Si Symons reprodujo juegos sonoros de aliteraciones y paralelismos, por otro lado, quita el del primer verso y

lo agrega en el cuarto, con una verdadera intromisión de «shame" ( vergüenza

) inesperada e inadecuada para el poema de San Juan, que evidentemente Symons usa para hacer resonar con « them », la última palabra del verso final (también innecesariamente alargado). Pero el verso « All ceased and I was not » es un verdadero hallazgo sonoro y sintáctico para repetir en inglés el hallazgo del poema de San Juan. Por eso creo que en el no infiel

Borges contempla adecuadamente ambos aspectos, buenos y malos, con una paradoja, en la que vuelve a resaltar la importancia del rasgo formal en la traducción, y de la fidelidadpara con el original.

5) En « El oficio de traducir » (323), propone que no se debe añadir un énfasis que no esté 
6) En «La música de las palabras y la traducción » (85), destaca -como ya dijimos antes y de acuerdo con Tinianov- la importancia de considerar el contexto de la palabra en el original. Y el original mismo, como en el caso del par Baudelaire y el traductor Stefan

George : « pues las personas interesadas en Baudelaire -y a mí Baudelaire me ha interesado mucho- entienden que las palabras proceden de Baudelaire ; es decir piensan

\section{firma de autor}

(nombre-de-autor o estilo, en el sentido foucaultiano, de un tipo de discurso ; firma, en términos de Derrida (1971 y 1984) : es decir, una firma de autor que en realidad se identifica con un quantum formal(Derrida 1996)al que se debe respetar como laformadeloriginal.

La pretensión de minimizar el poder del original deviene una mera expresión de deseo en la conferencia « La música de las palabras y la traducción » cuando Borges dice que si los textos fueran independientes, uno podría quizás juzgar la traducción como más bella que el original, pero dice esto « desgraciadamente, no puede ser así », como cuando concluye " pero yo desgraciadamente soy Borges » enNueva Refutación del Tiempo.

Así, como Benjamin, Borges admite que la traducción siempre se piensa en relación con el original, porque se trata de una relación entre lenguas y formas, y que la primera es laauténtica

, porque tienen status diferente dentro de la literatura. Borges parece decir que no hay escape para ello, al menos en este contexto histórico de la literatura en la que nos encontramos aún hoy.

Veamos ahora otro campo de la contradicción borgeana :

los diferentes ejemplos que da como atributos de unatraducción literal

en la misma conferencia, donde parece estar luchando contra su propio discurso rector previo. Por otro lado, cómo diferenciar

literalidaddefidelidad , que él considera fundamental y que se encuentra siempre como parámetro de sus comentarios sobre traducciones. Me atrevería a decir que la fidelidad requerida por Borges se acerca mucho a lo que he llamado

literalidad productiva

. Lo que él define para su propia traducción de Whitman como una oscilación entre « la interpretación personal [toda traducción es una lectura] y el rigor resignado » [hay que respetar el modo de decir-repetir del original y recrearlo con rigor] (1996: 160).

He aquí los diferentes modos de hablar sobre literalidad en este texto, incluidos en la 
1- Traducción palabra por palabra : coincide con Mathew Arnold en rechazar los énfasis «falsos ", extrañeza que no está en el original, a los que las versiones literales suelen conducir pero agrega que también pueden llevar a la « novedad y a la belleza » $(87)$.

2- Mantiene una posición ambigua frente al procedimiento de la literalidad : si, por un lado, le adjudica un origen teológico, que implica no alterar la palabra divina (ésa sería la concepción romántica de su « Dos maneras de traducir » de 1926) ; sin embargo cuando esa alteración se produce, como veíamos en el caso de Whitman o Shakespeare, la deplora consistentemente. En contradicción con el comienzo de la conferencia concluye que hoy « todo el mundo es partidario de las traducciones literales porque una traducción literal siempre nos produce esas leves sacudidas de asombro que esperamos » (92).

3- Observa el « sentido histórico » como hecho que nos abruma : habrá un tiempo en que no nos interesen los « hechos biográficos o históricos, los datos cronológicos » para considerar la literatura. Él mismo evidentemente no puede escapar a ellos, como cuando lee a Emily Dickinson ( «la encerrada sin amor ») o a Whitman (« el gran hombre americano », 95). Ese sentido histórico hace prevalecer las palabras « auténticas » del original, como dijo a propósito de Baudelaire ; y exige también una fidelidad a ese original.

A pesar de lo expuesto antes, la literalidad vuelve a ser descartada de plano unos pocos

años después en « El oficio de traducir », de 1976 ; y luego vuelve a ser plenamente elogiada en el Prólogo a las traducciones de Ocampo, de 1985, como veremos en detalle en lo que sigue. Citamos, entonces, dos casos más en los que Borges vuelve a polemizar con sus propias afirmaciones : bien podríamos decir que sus posiciones sobe la traducción hacen honor a sus laberintos. El primero es un texto de 1939, nuevamente a propósito de

fidelidad(por negación) y a contrastar original y traducción en la reseña de A Shakespeare Anthology

(1999 : 214-215). Se me permita la extensa cita para comprender bien el punto de vista de Borges :

What seest thou else In the dark-backward and Abysm of Time?

En la primera página dice Shakespeare :

$$
\text { Let the bird of loudest lay }
$$

On the sole Arabian tree, Herald sad and trumpet be:

To whose sound chaste wings obey.

Y en la 487:

Y en la 234 :

The very place put toys of desperation...

He trasladado esos ilustres y compactos fragmentos porque demuestran la omnipotencia verbal de Shakespeare y la incapacidad o

infidelidad

de sus traductores. Luis Astrana Marín, enfrentado por el tercero, traduce :

El solo sitio inspira ideas de desesperación.... Por el segundo :

Que el ave de canto más agudo, que se posa en el árbol solitario de la Arabia, sea el heraldo y

triste clarín a cuyo son obedecen los castos alados.

Por el adverbio sustantivado del primero:

¿Qué ves ahora en las tinieblas del pasado y en el abismo del tiempo?

Un gustador de Joyce o Mallarmé sería, tal vez, el mejor traductor de Shakespeare. 
Por supuesto, Borges tiene mucha razón en su crítica a estas pobres traducciones de Shakespeare : el último ejemplo suena un poco a tango, aunque el traductor sea español y le quita la grandiosidad del tono shakesperiano hasta con la resta de las mayúsculas -que luego heredará Dickinson- y la falta de la transformación del adverbio en sustantivo, al neutralizarla con la palabra común pasadoy olvidando así la bella aliteracióndark-backward ${ }^{14}$; y luego, elegirideas para transponertoys

es realmente una desdichada elección, lo mismo que reducir la imagen muy concreta, visible y casi palpable de wingsal alambicadoalados

. Sorprende gratamente la última frase de Borges, en la cual se vuelve a destacar la importancia del entrenamiento en la lectura de una forma tan singular y misteriosa como es la poesía, por eso -dice- aquellos que han sentido pasión por la forma en Mallarmé o Joyce podrían quizásser buenos traductores de la potencia verbal de Shakespeare.

En el segundo texto volvemos al Prólogo a las traducciones de Silvina Ocampo, en las que aparece otra vez una elogiable noción de "literalidad » como respeto del original, aunque ello contraste con lo realizado por Ocampo : He sospechado que el concepto de versión literal, desconocido a los antiguos, procede de los fieles que no se atrevían a cambiar una palabra dictada por el Espíritu. Emily Dickinson parece haber inspirado a Silvina Ocampo un respeto análogo. Casi siempre, en este volumen, tenemos las palabras originales en el mismo orden.

No es cotidiano el hecho de un poeta traducido por otro poeta. Silvina Ocampo es, fuera de duda, la máxima poeta argentina ; la cadencia, la entonación, la pudorosa complejidad de Emily Dickinson aguardan al lector de estas páginas, en una suerte de venturosa transmigración. (1985:11-12)

Es hora de preguntarse una vez más qué entendía Borges por literalidad o fidelidad. Con

la ambivalencia que lo caracteriza a la hora de hablar de traducción, Borges parece

in- fidelidadde los traductores de Shakespeare, Whitman o San Juan de la Cruz, y elogiar la literalidaden el trabajo de Ocampo, así como lafidelidad

de Roy Campbell cuando llega a una nueva traducción de San Juan ; y aún en sus propias traducciones parece ser claramente fiel

al dibujo que los versos de cada poema diseñan y al tono de su respiración. Cuando da las causas del elogio de la supuesta literalidad de Ocampo o de la fidelidad de las buenas traducciones, se halla muy cerca de nuestro argumento sobre la forma del fantasma abstracto o mapa rítmico, partitura flotante, potencia verbal. Sin embargo, para el caso de

Ocampo ese plan de trabajo trazado por Borges precisamente es el que la traductora contradice con regularidad, como hemos intentado demostrar en nuestros trabajos previos. Si por un lado, Ocampo sacrifica el tono breve y conciso de Dickinson en aras de algún tipo de « literalidad », en realidad está siendo fiel a la cadencia del español, no a la del original, como en el ejemplo que sigue, muy cercano al criticado por Borges para la traducción de León Felipe :

Life's little duties do - precisely

Las pequeñas obligaciones de la vida - cumplo meticulosamente - 
Si aquí se trata, entonces, de un engañoso respeto por el original, en otros casos el supuesto respeto se desvanece por completo con literales “invenciones »-como el ejemplo que vimos en la nota 10 - que parecen dar cuenta de una imposibilidad de traducir la extrañeza del original. Ocampo parece rendirse ante la dificultad y cambia los guiones de lugar, organiza de un modo coherente en la traducción lo que aparece sin coherencia en el original ; y, finalmente, coloca nexos y conectores muy propios del español pero ausentes en el estilo elíptico y ambiguo de Dickinson, un hipérbaton de la ya perse

sintética lengua inglesa. Con lo cual, Ocampo cede a una de las tentaciones que acucian al traductor : volver más « legible » el original para el lector en la lengua de llegada, ser un « mediador » entre el par lector-autor, como quería Ricoeur y nosotros rechazamos, al igual que rechazamos el regreso a un incomprensible sujeto en términos de Meschonnic (2007). Si en el plano del mapa rítmico-partitura flotante nos movemos en un campo inmanente e impersonal, allí debe llegar el traductor al leer el poema, y la firma sólo nos indica un modo de repetir

en la huella del oído refinado de la escucha (Emerson, 1844). La traducción de Ocampo, en cambio, parece responder a las fuertes alianzas estéticas y de clase social que la tenían apresada al escribir su propia poesía ; y que sí quizás pudo derribar en otro género, la narrativa, al igual que Norah Lange. En poesía, Ocampo no pudo abandonar al patrón

Borges

15

, y el canon domina su traducción de una obra tan revulsiva como la de Dickinson, cada vez que aquieta las aguas del poema, atempera su tendencia a lo físico y a lo concreto, haciéndolo fugar hacia la emoción sentimental, cuando el texto de Dickinson se aparta expresamente de ese campo, para constituir otro, en el que no deja de estar presente la emoción pero en un nivel alejado del lugar común previsto para la mujer de la época. En el prólogo al libro de las traducciones de Ocampo, Borges vuelve a insistir en su prejuicio de género, el mismo que le había hecho menospreciar la poesía de Alfonsina Storni

. De Dickinson destaca, además de su deseo de no publicar y de la intensidad de sus versos : « No hay, que yo sepa, una vida más apasionada y más solitaria que la de esa mujer. Prefirió soñar el amor y acaso imaginarlo y temerlo ». En ese sentido actúa también muchas veces la traducción de Ocampo, en la recurrencia de elegir lo sentimental-emotivo en lugar de lo concreto propio de Dickinson, así como insiste en llevar el poema a un plano más íntimo (coloca pronombres de primera persona mi-me

donde no los hay en el original, por ejemplo), quitándole al poema de Dickinson el tono metafísico-filosófico, a veces seco y enérgico, que suele imbricarse con lo cotidiano y emotivo.

En otras palabras, Borges, en contradicción con sus postulados más fuertes previos ${ }^{17}$ , elogia aquí la « literalidad » de las traducciones de Ocampo, con los siguientes rasgos : el respeto al original como « divino », tanto en la sintaxis del original como en el orden de palabras, y el respeto a las cualidades del quantum formal 
de Dickinson : « cadencia, entonación, pudorosa complejidad ». Se trata de un respeto por la forma-de-decir o de repetir del original, que en la lengua de llegada organiza Ocampo en « venturosa transmigración » : se trata del fantasma de una repetición que encarna en otras palabras, que lo alojan. Por ende, Borges aquí acuerda con nuestros criterios básicos sobre la traducción de poesía, elaborados a partir de Benjamin. Lo curioso es que esos criterios son enunciados en abstracto y como deseo más que como hechos observables en las traducciones de su amiga Ocampo, quien comete todo tipo de torpezas en relación con dichos criterios. Borges debió seguramente pasarlas por alto, a menos que haya dejado como un guiño cómplice para futuros lectores el descubrimiento de esas discrepancias evidentes entre lo que en su Prólogo dice haber leído en las traducciones de Ocampo y lo que las traducciones de Ocampo efectivamente hacen. $\mathrm{Si}$, en efecto, ellas producen transformaciones desde el original para logar un significado más comprensible

, y normalizan el poema, quitándole su extrañeza singular, bien lejos están de cumplirse los elogios de Borges en su Prólogo de presentación, que a la luz de estos hechos se transforman más bien en una trampa irónica.

Del mismo modo, resulta asombroso encontrar una aparente concepción romántica de la poesía en Borges que se desprende de sus continuos subrayados sobre la emoción del que escribió el poema, como eje fundamental de lectura : «tenemos que considerar el poema como fruto de una profunda emoción » (« La música de las palabras y la traducción », 82); o de « una emoción verdadera », explícita en la conferencia siguiente ( Pensamiento y poesía ", 116-117). Sin embargo, si leemos en profundidad estos textos dicha emoción se traduce en elemento formal, en composición musical y sonora, una unidad inseparable y difícil de traducir (« Pensamiento y poesía », 97). Antes, en 1937, nos había hablado de la poesía como un efecto físico

. Ahora, resalta con Stevenson la naturaleza dual de la poesía : el poeta convierte en « algo mágico » las palabras destinadas al « común comercio de la vida cotidiana » (98). Por lo tanto, no importa en realidad el significado de las palabras, más bien la poesía devuelve el lenguaje a su fuente originaria, la misma que se relaciona con los orígenes de la música

(Ver Muschietti

et al.2014). En 1964, dice a propósito de Shakespeare :

Como sucede con todos los genuinos poetas, la operación estética en Shakespeare es anterior a la interpretación y no la requiere ; poco importa para el de :

inmediato efecto mágico The mortal moon bath her eclipse endure que el verso se refiera a una dolencia de la Reina Virgen, Elizabeth, o la luna del cielo o (según lo más probable) a los dos. 
Entonces, la curiosa coincidencia se da con la tesis de Kristeva y Deleuze : la poesía propone una lengua viva, no del diccionario, donde importa lo « concreto », lo sensorial, el afecto y efecto por sobre el significado (104 y 105), que resulta así desviado, desplazado

de su lugar de poder. Las palabras en poesía, afirma Borges emblemáticamente, « no significan nada, no han sido escritas para significar nada ; y sin embargo se sostienen » (107). Destaca la importancia de la música ligada a una memoria original, y éstas a su vez a la emoción generadora. Parece acordar otra vez con concepciones postestructuralistas, ahora con Derrida (1988) y su deliciosa definición : « La poesía espera ser aprendida de

par coeur

) como una música ». Con Kristeva y Olson, agregaría Borges a estas palabras de Derrida, que esa música está anclada a la memoria de una emoción primera y se proyecta como fuerza hacia una emoción futura. Por eso Borges admiraba tanto la palabra de la poesía, de la cual él, tristemente, no se sentía capaz ; por eso, finalmente y más allá de cualquiera de sus afirmaciones programáticas y a pesar de sí, no pudo sino pensar la traducción de poesía como tarea de respeto a un quantum formal y sonoro del original, partitura flotante o jeroglífico enigmático para los patrones del sentido común, esos que cada traductor debe abandonar en aras de una escucha flotante, librado a las fuerzas de la creación poética.

\section{BIBLIOGRAFÍA}

Agamben, Giorgio [1978].Infancia e historia. Buenos Aires : Adriana Hidalgo, 2001

Benjamín, Walter [1923]. « La tarea del traductor ».Angelus Novus

. Barcelona : Edhasa, 1971. 127-143.

Borges, Jorge Luis. « Problemas de la traducción ».La Opinión Cultural,21 de septiembre de 1975.

También en :Textos recobrados. Buenos Aires : Emecé, 1997.

Borges, Jorge Luis. « Prólogo » aPoemas

de Emily Dickinson. Traducción de Silvina Ocampo. Barcelona : Tusquets, 1985.

Borges, Jorge Luis.Obras Completas IV. Buenos Aires : Emecé, 1996.

Borges, Jorge Luis.Textos recobrados.Buenos Aires : Emecé, 1997.

Borges, Jorge Luis.Borges en Sur(1931-1980). Buenos Aires : Emecé, 1999.

Borges, Jorge Luis.Arte poética. Seis conferencias. Barcelona : Crítica. 2001.

Cage, John [1961]. « Experimental Music : Doctrine ».Silence

. Middletown : Wesleyan University Press, 1973.

Deleuze, Gilles.Repetición y diferencia.Barcelona : Anagrama, 1981.

Deleuze, Pilles.Qué es la filosofía. Barcelona : Anagrama, 1993.

Deleuze, Pilles. « La inmanencia : una vida ».Philosophie47 (1 de septiembre de 1995) : 3-7. 
Derrida, Jacques [1971]. « Firma, acontecimiento y contexto ».La escritura y la diferencia . Barcelona : Anthropos, 1989.

Derrida, Jacques.Signeponge. Paris : Seuil, 1984. En inglés edición bilingüeSigneponge/Signsponge .Columbia University Press, 1985.

Derrida, Jacques. « ¿Qué es poesía? ».Er. Revista de Filosofía

VI, 248 (invierno1989/verano 1990) : 165-170.

Derrida, Jacques.El monolingüismo del otro. Buenos Aires : Manantial, 1997.

De Man, Paul. «Conclusiones :La tarea del traductorde Walter Benjamin ».Resistencia a la teoría

. Madrid : Visor, 1990. 115-162.

Emerson, Ralph [1844]. « The Poet ».Nature and other writings. Boston-London : Shambala, 2003.

Foucault, Michel.La arqueología del saber. México : Siglo XXI Editores, 1969.

Efraín Kristal,Invisible work.Borges and Translation, Nashville : Vanderbilt University Press, 2002.

Lacan, Jacques [1964-1973]. « La excomunión ».Los cuatro conceptos fundamentales del psicoanálisis. Buenos Aires : Paidós, 2005. 10-21.

Lacan, Jacques. «El inconsciente y la repetición ».

Los cuatro conceptos fundamentales del psicoanálisis.Buenos Aires : Paidós, 2005. 25-36.

Lowenberg, Carlton.Emily Dickinson's Textbooks. Lafayette, California, 1986.

Meschonnic, Henri.Ethique et politique du traduire.Paris : Verdier, 2007.

Muschietti, Delfina. « Prólogo ».Obras Completasde Alfonsina Storni. Buenos Aires : Losada, 2000.

Muschietti, Delfina. « Borges y Storni : la vanguardia en disputa ».Hispamérica95 (2003) : 21-44.

Muschietti, Delfina. «Leer y traducir : restos y robos melancólicos ».Filología

XXXIII, 1-2 (2000-2001) : 269-288. Fragmentos en línea : http://www.poesiaytraducción.com

Muschietti, Delfina. «Traducción de poesía : forma, repetición y fantasma en el estudio comparado de traducciones de Emily Dickinson (Silvina Ocampo, Amelia Rosselli)».

Orbis Tertius12 (2006).

http://www.orbistertius.unlp.edu.ar/numeros/numero-12/8-muschietti.pdf

Muschietti, Delfinaet al.Traducir poesía. La tarea de repetir en otra lengua

. Buenos Aires : Bajo la luna, 2013.

Muschietti, Delfinaet al.Traducir poesía. Mapa rítmico, partitura y plataforma flotante

. Buenos Aires : Paradiso, 2014.

Naranjo Mariscal, José. « La repetición en Freud y Lacan ». Instituto del campo freudiano. Sección clínica de Barcelona, 2002.

http://www.scb-icf.net/nodus/default.htm

Olson, Charles [1950]. « El verso proyectivo » (Trad. de Rodrigo Caresani). Muschiettiet al. Traducir poesía. La tarea de repetir en otra lengua. Buenos Aires : Bajo la luna, 2013. 367-384.

Pasolini, Pier Paolo. « Notizia ».Il Manabò6 (1963) : 66-69.

Pastormerlo, Sergio. « Borges y la traducción ».Borges Studies Online

.J. L. Borges Center for Studies \& Documentation, 2001.

http://www.uiowa.edu/borges/bsol/pastorm1.shtml

Ricoeur, Paul.Sobre la traducción. Buenos Aires : Paidós, 2005 
Tinianov, Iouri [1923].El problema de la lengua poética. Buenos Aires : Siglo XXI, 1970.

Ulla, Noemí [1982].Encuentros con Silvina Ocampo. Buenos Aires : Leviatán, 2003.

Waisman, Sergio.Borges y la traducción. Buenos Aires : Adriana Hidalgo, 2005.

Yankélévitch, Vladimir [1961].La música y lo inefable.Barcelona : Alpha Decay, 2005.

\section{NOTAS}

1.

Como dice Lacan : « Pero el análisis no consiste en encontrar, en un caso, el rasgo diferencial de la teoría, y en creer que se puede explicar con ello por qué su hija está muda, pues de lo que se trata es dehacerla hablar » (Lacan 2005 : 19).

De eso se trata tanto con la forma en la poesía como luego con la repetición en las elecciones de traducción : de hacerlas hablar.

2.

Función verbal

llamaba acertadamente Tinianov a ese pasaje que encontramos en la lengua del poema para pasar como vasos comunicantes al mundo cultural, social e histórico que no es el poema y en el que el poema se inserta como producción.

3. Esta concepción aparece plenamente desarrollada en Muschiettiet al., Traducir poesía. Mapa rítmico, partitura y plataforma flotante, Buenos Aires : Paradiso, 2014.

4.

En la conferencia « El enigma de la poesía » (Borges 2001 : 15-35). Borges cita las palabras del pintor Whistler : « El arte sucede », y agrega : « Es decir, hay algo misterioso en el arte. Me gustaría tomar sus palabras en un sentido nuevo.Yo diré :

El arte sucede cada vez que leemos un poema » (21).

5.

Una de las técnicas más preciadas y preciosas para seguir la repetición del original es escuchar en voz alta los resultados posibles de las diferentes elecciones a la hora de traducir cada verso. Escuchar-se decir en el poema traduciendo el ritmo del original.

6. Elegimos llamarloabstractopara deslindarlo delneutro , que se utiliza en los medios de comunicación masiva.Elabstracto

es un español que no se habla, es un instrumento para la traducción, para alojar la lengua-forma traducida.

7. «Pero creo que se comete un error cuando se insiste en las palabras vernáculas. Yo mismo lo he cometido.

Creo que un idioma de una extensión tan vasta como el español es una ventaja y hay que insistir en lo que es universal y no local » (Borges 1997 [1975] : 323).

8.

Según el testimonio de los alumnos norteamericanos que frecuentan mi Seminario de Poesía y Traducción, en la Universidad de Buenos Aires.

9.

Así lo testimonia Kate Scott Anthon, en una carta de octubre de 1917 dirigida a Martha Dickinson, sobrina de Emily, cuando recuerda esos « maravillosos atardeceres en casa de Austin

[Dickinson] », cuando Emily estaba « a menudo en el piano tocando extrañas y bellas melodías, todas de su propia inspiración ».

(Citado en Carlton Lowenberg 1986) 
Veamos el final de una estrofa del Poema J 258. El original de Dickinson dice :

There's a certain Slant of light,

Winter Afternoon -

That opresses, like the Heft

of Cathedral Tunes -

Traduce Ocampo :

Hay un cierto sesgo de luz,

10.

en las tardes de invierno-que oprime, como

la profundidad de las catedrales(

el subrayado es nuestro)

«la profundidad de las catedrales” termina con el oxímoron dickinsoniano, que reúne opresses-Heft(opresión y peso) conTunes

, una manera cotidiana y ligera de mencionar una melodía que, a su vez, está adjetivada por el sustantivo majestuoso

Cathedral.

Todo el juego barroco queda arrasado por la imagen inventada por Ocampo. Ello se hace aún más evidente cuando uno constata en otros poemas de Dickinson la frecuente aparición de Hymn

, un modo solemne de música que, según el sentido común, hubiera correspondido mejor a la música propia de las catedrales.

(Las dos recopilaciones mayores de la obra de Dickinson fueron realizadas por Thomas Johnson

The complete poems of Emily Dickinson

en 1955, y luego la cronología fue revisada por Ralph W. Franklin en

The Editing of Emily Dickinson : A Reconsideration, Madison : Univerity of Wisconsin Press, 1967.

Hoy existe una nueva edición de Franklin, The poems of Emily Dickinson

, Hardcover, 1998, de varios tomos, que suele considerarse la más erudita. La J o la F que precede

el número de poema de Dickinson indica de qué recopilación se toma. Prefiero la de Johnson porque es la que leyó Sylvia Plath cuando comenzó a escribir en 1955).

11.

Hemos encontrado una coincidencia en el título de Efraín Kristal,

Invisible work. Borges and Translation(2002).

12.

La misma Silvina Ocampo incurre en ese error, y muchas veces parece elegir la primera acepción dada por el diccionario sin considerar el contexto del poema y de la totalidad de la obra de

Dickinson.

13.

El subrayado en las palabras de Borges es mío en todos los casos.

Los poemas aparecen en cursiva en el texto original (291-292).

14.

Podríamos traducir este bello fragmento, y recuperar algo delmodo de decir de Shakespeare y su grandiosidad:

¿Qué otra cosa ves

En el oscuro-atrás y Abismo del Tiempo?

15. Resulta muy interesante seguir enEncuentros con Silvina Ocampo (Ulla 2003), todas las veces que Ocampo cita a Borges como una autoridad en materia de crítica literaria, y al mismo tiempo 
desliza tímidamente algunos desvíos de las posiciones borgeanas. Borges es siempre citado como autoridad : ya sea para legitimar Ocampo algunos de sus propios juicios, ya sea para esbozar tímidamente una oposición a los juicios de Borges. Especialmente productivo es leer la respuesta que Ocampo ofrece frente a la pregunta de cuáles autores le gustaba leer : « Me gustaba sobre todo la poesía, aunque no estuviera muy de acuerdo con Borges en su admiración por alguna poesía ». Los autores elegidos por Ocampo son significativamente poetas más bien tradicionales : Banchs, Mastronardi, Martínez Estrada (« pero no estoy de acuerdo con Borges en que sea el mayor poeta que tenemos ", 130).

A pesar de esas reflexiones laterales en disonancia, resulta evidente que el patrón-Borges resultó para Ocampo muy difícil de sortear.

Aún en el caso de las traducciones de Dickinson, Borges actuaría como recurso de autoridad : «y como en ese tiempo traducía a Emily Dickinson, hacía preguntas a Borges sobre algunas palabras en inglés cuya precisión en español presentaba dudas. Confiaba muchísimo en él y era muy agradable aquella escena donde los dos amigos opinaban, discutían, perseguían el ajuste semántico de la palabra por traducir ».(172)

16.

Es interesante leer la cercanía de posición y de estrategias discursivas que conectan la ruptura del canon en Emily Dickinson y en Alfonsina Storni.

Ver mi análisis en Muschietti 2000.

Borges deslinda, por su lado, la literatura escrita por varones de la literatura sentimental destinada a las mujeres, "muchachas" que florecen en las "quintas" : en oposición a ese canon se destaca la disonante poesía de Alfonsina, a la que Borges destina la ya famosa frase descalificadora : "sin incurrir en las borrosidades y chillonerías de comadrita que suele inferirnos la Storni". He trabajado en detalle estas demarcaciones en Muschietti 2003.

17.

Muy interesante resulta la lectura de Sergio Pastormerlo (2001), quien coincide con nosotros al señalar las posturas contradictorias de Borges en su corpus central y programático sobre traducción.

Yo me he dedicado, en cambio, a leer textos laterales de Borges que apuntalan la lectura de Pastormerlo desde el Laboratorio de Traducción borgeano.

\section{RESÚMENES}

Este trabajo se inscribe en la propuesta de una nueva Escuela de Traducción Poética. Las premisas teóricas de Walter Benjamin (1923) y Giorgio Agamben (1978) enmarcan nuestra tarea como una Nueva Filología, de carácter interdisciplinario

.Traducir el poema será hallar una nueva forma que, como afirma Benjamin, debe capturar el modo-de-decir del original,fórmula ampliada enel modo-de-repetir del original

. El lector-receptor debe aguzar la capacidad para leer esas intensidades de la repetición que viajan entre posiciones móviles (la del poeta, la del crítico-traductor-escritor), que se intersectan y ponen en contacto diferentes horizontes culturales y tendencias frente a la lengua. Para ello debe adoptar una posición de escucha flotante

(Freud), libre de prejuicios culturales y de lectura, para captar la extrañeza que diseña el original : 
mapa rítmicoopartitura flotanteque es la huella escrita por el poeta desde el contacto con la plataforma flotante

, plano de abstracción cualitativa o inmanencia trascendental deleuziana. Desde estas premisas revisamos los textos laterales de Borges (reseñas, prólogos, conferencias) en los que observamos su tarea en el Laboratorio de Traducción, como traductor o como lector de otras traducciones : allí constatamos un sorprendente contra-canon, que desdice sus propias y difundidas proclamas sobre las nociones de autor y original.

Ce travail s'inscrit dans le cadre d'une Nouvelle École de Traduction poétique, dont les propositions sont inspirées par les théories de Walter Benjamin (1923) et Giorgio Agamben (1978) menant vers une Nouvelle Philology Interdisciplinaire. La traduction du poème est entendue ici comme la découverte d'une forme nouvelle qui-comme le dit Benjamin- doit saisir lamanière-de-dire- de l'original, formule que nous élargissons àla manière-de-répéter-de l'original - Le lecteur-récepteur se doit d'aiguiser sa capacité à lire les différentes intensités de la répétition dans leur passage d'un émetteur à un autre (le poète, le critique-traducteur -et-écrivain), car ces émissions, en se croisant, mettent en contact divers horizons culturels et diverses tendances en relation avec la langue. Pour ce faire le lecteur se place dans une attitude d'écoute flottante(Freud), libérée de préjugés culturels et d'habitudes de lecture afin de capturer l' étrangéitéde l'original : autrement dit, lacarterythmiqueoupartition flottante , trace écrite par le poète en contact avec laplateforme flottante

-un plan d'abstraction qualitative ou d'immanence transcendantal (Deleuze)-. A partir de ces postulats nous passons en revue des textes critiques de Borges (comptes-rendus, préfaces,

conférences) afin de l'observer à l'œuvre dans le Laboratoire de Traduction, en tant que traducteur et en tant que lecteur de traductions. Nous vérifions ainsi la présence d'un étonnant contra-canon dans ces écrits, qui contredisent ses positions bien connues sur les notions d'auteur et de texte original.

This article can be read within the frame of a New School of Poetry Translation, following the Walter Benjamin and Giorgio Agamben theoretical premises that lead us to a New Interdisciplinary Philology. In order to translate the poem a new form must be found -like Benjamin says-, able to capture from the original itsway-of-saying ; or, I add,its way-of-repeating

The reader must increase his capacity to read the intensities that come from the repetition, going through moving positions (the poet, the critic-translator-writer), that interconnect different cultural horizons and tendencies referred to language. He must adopt a flouting attention

(Freud's term), free from cultural prejudices and reading habits in order to apprehend the "estrangement" drawn by the original : a

rhythmical maporflouting score

, which means the track written from the contact between the poet and theflouting platform

(a plain of qualitative abstraction or deleuzian transcendental immanence) where the superrefined ears (Emerson) reach the unknown. From these premises we read the lateral texts of Borges (short readings, introductions, conferences), where we see him working on the Translation Laboratory, as a translator or as a reader of other's translations : we find a surprising contra-canon, which contradicts his known and widely spread statements about the notions of author and original. 
ÍNDICE

Mots-clés: traduction de poésie, carte rythmique, partition, plateforme flottante, Borges

Keywords: poetry translation, rhythmical map, score, flouting platform

Palabras claves: traducción de poesía, mapa rítmico, partitura, plataforma flotante

\section{AUTOR}

DELFINA MUSCHIETTI

Universidad de Buenos Aires

delfinam34@gmail.com 